
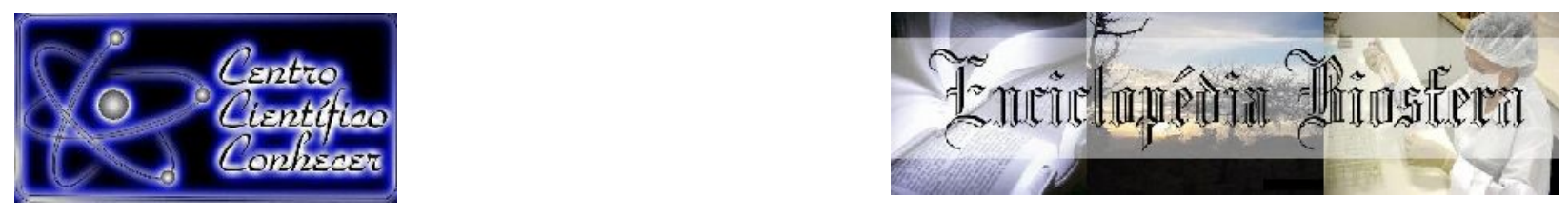

\title{
TENDÊNCIAS DE VARIABILIDADE ESPAÇO-TEMPORAL PLUVIOMÉTRICA NA BACIA HIDROGRÁFICA DO RIO ARAGUAIA
}

Dênis José Cardoso Gomes ${ }^{1}$, Nedilson Sanches Ferreira ${ }^{1}$, Aline Maria Meiguins de Lima $^{2}$

1 - Graduandos em Meteorologia da Universidade Federal do Pará, Laboratório de Estudos e Modelagem Hidroambientais - LEMHA (deniss.feg@gmail.com).

2 - Dr ${ }^{\mathrm{a}}$. Universidade Federal do Pará, Programa de Pós-Graduação em Ciências Ambientais.

Recebido em: 06/04/2019 - Aprovado em: 10/06/2019 - Publicado em: 30/06/2019 DOI: 10.18677/EnciBio_2019A126

\section{RESUMO}

O estudo climático é essencial para a gestão dos recursos hídricos de uma bacia hidrográfica, podendo impactar a esfera socioambiental e econômica, função de sua influência da disponibilidade hídrica existente. O objetivo deste trabalho foi analisar a variabilidade espaço-temporal pluviométrica na bacia hidrográfica do Araguaia, associada a fenômenos climáticos, diferenciando as áreas de maior e menor potencial hídrico. O rio Araguaia está localizado na parte central do Brasil, com extensão de $384,818 \mathrm{~km}^{2}$, vegetação de cerrados e clima tropical quente. Os dados pluviométricos foram provenientes da Agencia Nacional das Águas e os da Temperatura da Superfície do Mar adquiriu-se da NOAA (National Oceanic and Atmospheric Administration). Observou-se eventos de El Niño e La Niña e Dipolos do Atlântico influênciando na pluviosidade anual. $O$ trimestre mais chuvoso foi Dezembro, Janeiro e Fevereiro; e o menos chuvoso foi Junho, Julho e Agosto. Na época das cheias (Novembro-Abril) a pluviosidade variou de 59,2-304,8 $\mathrm{mm}$ e na estação de estiagem (Maio-Outubro) foi evidenciado mínima de 0,22 $\mathrm{mm}$ e máxima de $97,6 \mathrm{~mm}$. A climatologia observada variou de $1.446,0 \mathrm{~mm}-1.610,4 \mathrm{~mm}$ (baixa pluviosidade) até $1741,3 \mathrm{~mm}-1.834,2 \mathrm{~mm}$ (alta pluviosidade). A resposta chuva $\mathrm{x}$ vazão apresenta uma defasagem de cerca de 1 mês nas sub-bacias próximas á foz com o rio Tocantins. Os resultados mostraram que a bacia do rio Araguaia respondeu aos eventos de variabilidade climática, logo o seu monitoramento contínuo é necessário para avaliação de áreas suscetíveis a eventos extremos.

PALAVRA-CHAVE: Clima. Eventos extremos. Precipitação.

\section{TRENDS OF SPACE-TEMPORARY VARIABILITY OF RAINFALL IN ARAGUAIA RIVER BASIN}

\begin{abstract}
The climatic study is essential for the management of water resources in a river basin, which may impact the social-environmental and economic sphere, in the definition of existing water availability. The objective of this work was to analyze the spatial and temporal variability of rainfall in the Araguaia basin, associated with
\end{abstract}


climatic events, differentiating the areas with higher and lower water potential. The Araguaia River is located in the central part of Brazil, with an area of $384,818 \mathrm{~km}^{2}$, vegetation of cerrado and warm tropical climate. Rainfall data were obtained from National Water Agency and Sea Surface Temperature data were obtained from National Oceanic Atmospheric and Administration. It was observed some events of El Niño e La Niña and Atlantic Dipole influencing in the annual rainfall. The rainiest quarter was December, January and February; and the less rainy was June, July and August. During the flood season (November-April) rainfall ranged from $59.2 \mathrm{~mm}$ and up to $304.8 \mathrm{~mm}$ and in the dry season (May-October) minimum of $0.22 \mathrm{~mm}$ and maximum of $97.6 \mathrm{~mm}$ were observed. The climatology ranged from 1,446.0-1,610.4 $\mathrm{mm}$ (low rainfall) to $1741.3-1834.2 \mathrm{~mm}$ (high rainfall). The rainfall $\mathrm{x}$ flow response presents a lag of about 1 month in the sub-basins near the mouth of the Tocantins river. The results showed that the Araguaia River basin responded to events of climatic variability, so its continued monitoring is necessary for the evaluation of areas susceptible to extreme events and the adoption of preventive measures to reduce social and environmental vulnerability.

KEYWORDS: Climate. Extreme events. Precipitation.

\section{INTRODUÇÃO}

Bacias Hidrográficas $(\mathrm{BH})$ são conjuntos de terras naturais de estudo e gestão composta por uma rede de drenagem com um rio principal e seus afluentes, no qual sua nascente é formada em regiões de relevos altos com bifurcações de águas, onde águas pluviais ora escoam superficialmente originando os rios e/ou infiltram-se no solo para a formação dos lençóis freáticos para posteriormente ser evaporada, sendo sua dinâmica paisagística impactada pelas mudanças uso e cobertura da terra (TEODORO et al., 2007; CAZULA; MIRANDOLA, 2010).

$\mathrm{O}$ ciclo hidrológico vinculado a uma $\mathrm{BH}$ é diretamente condicionado pelas condições climáticas. Ferreira e Mello (2005) afirmam que o clima de qualquer região é governado na maioria pela circulação geral da atmosfera. Barros e Balero (2012) e Rocha et al. (2018) destacam a importância das Frentes Frias (FF) e da massa Equatorial Continental (EC), além de outros mecanismos moduladores como o Anticiclone Subtropical Semifixo do Atlântico Sul (ASSAS), linhas de Instabilidade Tropicais (IT), Anticiclone Polar (AP), Frente Polar (FP), além da ZCAS (Zona de Convergência do Atlântico Sul) sugerida nos estudos de Borsato et al. (2012). A ação integrada destes na $\mathrm{BH}$ influencia diretamente seu sistema de recarga, uma vez que a principal interface é feita pela entrada (input) de água no sistema, realizado pela precipitação pluviométrica e sua sazonalidade.

A precipitação é uma das variáveis climáticas mais importantes em regiões tropicais, devido ser moduladora de outros elementos atmosféricos (DE SOUZA et al., 2015). A variabilidade pluviométrica afeta diretamente a população, a economia e o meio ambiente. O estudo climático de uma região possibilita uma melhor gestão dos recursos hídricos disponíveis otimizando atividades dependentes da água para várias finalidades como irrigação de culturas, geração de energia elétrica, abastecimento doméstico e industrial, além de subsidiar a prevenção de inundações e erosão hídrica do solo (SOUSA et al., 2007; RODRIGUES; BATISTELA, 2013).

Algumas $\mathrm{BH}$ estão em processo de degradação ambiental, por tanto a carência de informações sobre variabilidades climáticas dificulta no planejamento de preservação e restauração (SOUZA et al., 2012). A falta de informação hidrológica nas estações pluviométricas brasileiras é uma problemática 
recorrente e constatada pela comunidade cientifica (NASCIMENTO et al., 2010; WANDERLEY et al., 2012; SANTOS et al., 2014), isto dificulta o processo de pesquisas e uma análise mais consistente da variabilidade pluvial. Estas falhas são possivelmente devido a erros de codificação, mau funcionamento dos instrumentos, ausência de observador, falha na transmissão de dados (CORRÊA et al., 2016; MELLO et al., 2017).

Um exemplo de associação entre alteração da paisagem da $\mathrm{BH}$, demanda hídrica e monitoramento climático é a bacia do rio Araguaia, que além da importância hídrica, como principal afluente do rio Tocantins, é um rio de integração regional entre o Centro Oeste e o Norte do Brasil. Neste cenário, o objetivo deste trabalho foi analisar a variabilidade da precipitação espacial e temporal na bacia hidrográfica do Araguaia, associadas a ocorrência de fenômenos climáticos, verificando sua disponibilidade hídrica assim como suas áreas de maior e/ou menor potencial hídrico.

\section{Área de estudo}

\section{MATERIAL E MÉTODOS}

A Bacia Hidrográfica do rio Araguaia está localizada na parte central do Brasil, com a foz na região Norte. O rio Araguaia é o principal tributário do rio Tocantins, constituindo seu principal afluente. Sua BH drena áreas de vários estados (Pará, Tocantins, Mato Grosso e Goiás), possuindo a maior ilha fluvial do mundo (CASTRO, 2005; BRASIL, 2006). (Figura 01).
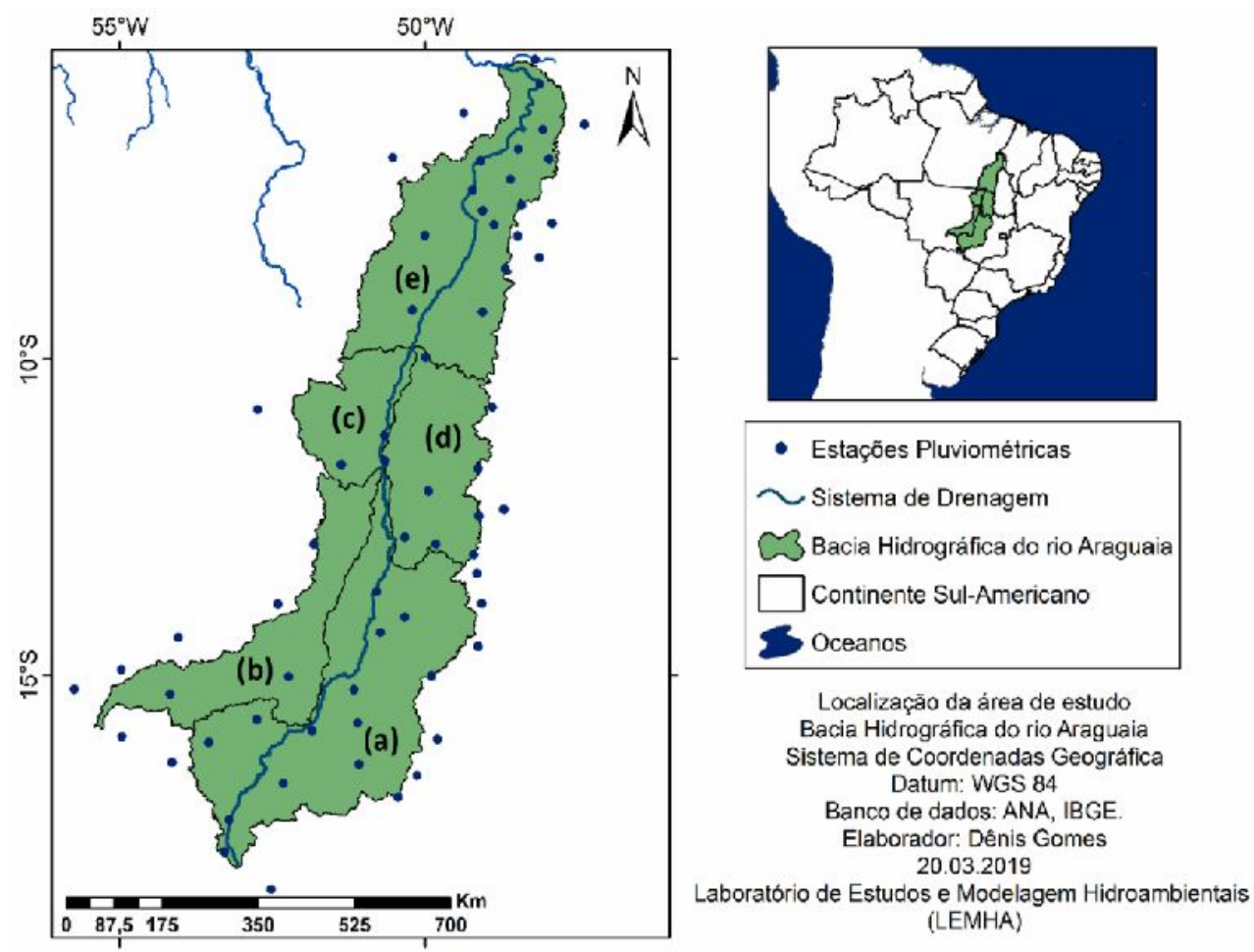

FIGURA 1. Bacia Hidrográfica do rio Araguaia e sub-bacias: a) Alto Araguaia; b) Rio das Mortes; c) Médio Araguaia; d) Cantão do Araguaia; e) Baixo Araguaia.

A BH possui uma população de 1.365.220 hab. Abrangendo uma área de aproximadamente $384,818 \mathrm{Km}^{2}$, sendo composta por 5 sub-bacias: a) Alto Araguaia, 
no qual nasce o rio nos altiplanos da Serra do Caiapó (850 m) no município de Mineiros - GO; b) Rio das Mortes, principal tributário da $\mathrm{BH}$; c) Médio Araguaia; d) Cantão do Araguaia; e) Baixo Araguaia, área onde há a confluência com o rio Tocantins, sendo considerado um rio de planície (cerca de $2000 \mathrm{~km}$ ) percorrendo uma cobertura vegetal predominantemente de cerrados (BRASIL, 2006; CHOUERI, 2013).

A climatologia da $\mathrm{BH}$ apresenta precipitações que variam de 1450 a 1850 $\mathrm{mm}$, com temperaturas do ar máximas e mínimas atingindo $35^{\circ} \mathrm{C}$ e $22^{\circ} \mathrm{C}$ e umidade relativa do ar média de $72 \%$ (BRASIL, 2019). A BH é formada por escudos cristalinos e bacias sedimentares, além de sua caracterização geomorfológica apresentar planícies, depressões, tabuleiros, chapadas e planaltos, sua pedologia é constituída por argissolos, cambissolos, chernossolos, gleissolos, latossolos, neossolos, plintossolos, sendo o conhecimento de aspectos geológicos e da paisagem fatores importantes que influenciam na variabilidade hídrica tanto superficiais como subterrâneos (BRASIL, 2006; BRASIL, 2018).

\section{Aquisição de dados}

Os dados pluviométricos foram adquiridos pelo banco de dados da série histórica da Agência Nacional da Águas (ANA) disponibilizados na plataforma HidroWeb (SOUZA et al., 2015), sendo utilizados apenas os dados consistentes (menor lacunas de falhas) de um período de 33 anos (1985 a 2017) com um número de 63 estações pluviométricas distribuídas dentro e algumas nas proximidades da bacia hidrográfica.

A National Oceanic and Atmospheric Administration (NOAA, 2018) disponibiliza dados de forma trimestral do Índice Oceânico Niño (ION), Temperatura do Atlântico Sul (TSA), mesmos índices utilizados por Nóbrega et al. (2014), onde apresenta as anomalias de temperaturas de superfície do mar. Quando o índice for maior que $+0,5^{\circ} \mathrm{C}$ por no mínimo 5 trimestres consecutivos será caracterizado como anomalia positiva (EI Niño); quando for menos que $-0,5^{\circ} \mathrm{C}$ respectivos, será considerado anomalia negativa (La Niña).

\section{Tratamento de dados}

A visualização dos dados pluviométricos foi feita pelo softwere Hidro 1.3 (BRASIL, 2019) e em seguida exportou-se para planilhas do softwere Excel 2016 para uma melhor manipulação dos dados (SANTOS et al., 2016; PENEREIRO et al., 2018). O preenchimento de falha (Eq. 1) das 63 estações pluviométricas foi realizado através do método de Ponderação Regional $(P R)$.

$P(\mathrm{x})=\frac{1}{3}\left(\frac{N x}{N a} P a+\frac{N x}{N b} P b+\frac{N x}{N c} P c\right)$

Onde: Nx é a precipitação mensal do posto pluviométrico que há falha; $\mathrm{Na}, \mathrm{Nb}$ e $\mathrm{Nc}$ é a precipitação média mensal dos postos pluviométricos próximos; $\mathrm{Pa}, \mathrm{Pb}$ e $\mathrm{Pc}$ é a precipitação do mês dos postos pluviométricos próximos.

Este método implica em complementar a carência de informações verificada por Oliveira et al. (2010) dos postos pluviométricos, no qual algumas considerações são feitas: média de no mínimo 3 estações próximas (clima similar) ao posto a ser preenchido e no mínimo 10 anos de dados, para homogeneizar o período de estudo visando uma melhor execução e análise estatística (BERTONNI ; TUCCI, 2009; FÉLIX, 2015; SANTOS et al., 2016; MELLO et al., 2017). 


\section{RESULTADO E DISCUSSÃO}

Segundo Santos et al. (2016) anomalia de Temperatura da Superfície do Mar (TSM) influenciam no regime pluviométrico da América do Sul tropical, apresentando uma resposta de defasagem em uma escala temporal mais que da TSM do Pacífico. O fenômeno de ENOS, El Niño - EL (aquecimento) e La Niña - EL (resfriamento), são osciladores naturais relacionados a anomalias de TSM que causam circulações anômalas de grande escala na atmosfera, impactando o sistema hidrológico da região, diminuindo (EL) e/ou aumentando $(\mathrm{LN})$ o valor destas variáveis (GRIMM, 2003; ARAÚJO et al., 2013; MOURA et al., 2018).

Observa-se na Figura 02 a oscilação da anomalia de TSM dos oceanos Atlântico (TSA) e Pacífico (ION), onde verifica-se um alto grau de anormalidade positiva nas águas superficiais Pacífico nos anos de $1987\left(1,28^{\circ} \mathrm{C}\right), 1997\left(1,17^{\circ} \mathrm{C}\right)$ e $2015\left(1,49^{\circ} \mathrm{C}\right)$, configurando eventos de El Niño forte nesses períodos distintos e diminuição das precipitações. Nestas águas, ainda pode-se observar um considerável resfriamento superficial nos anos de $1988\left(0,81^{\circ} \mathrm{C}\right), 1999\left(1,23{ }^{\circ} \mathrm{C}\right)$ e $2011\left(0,83{ }^{\circ} \mathrm{C}\right)$, favorecendo a formação de fenômenos de La Niña e aumento do montante pluviométrico.

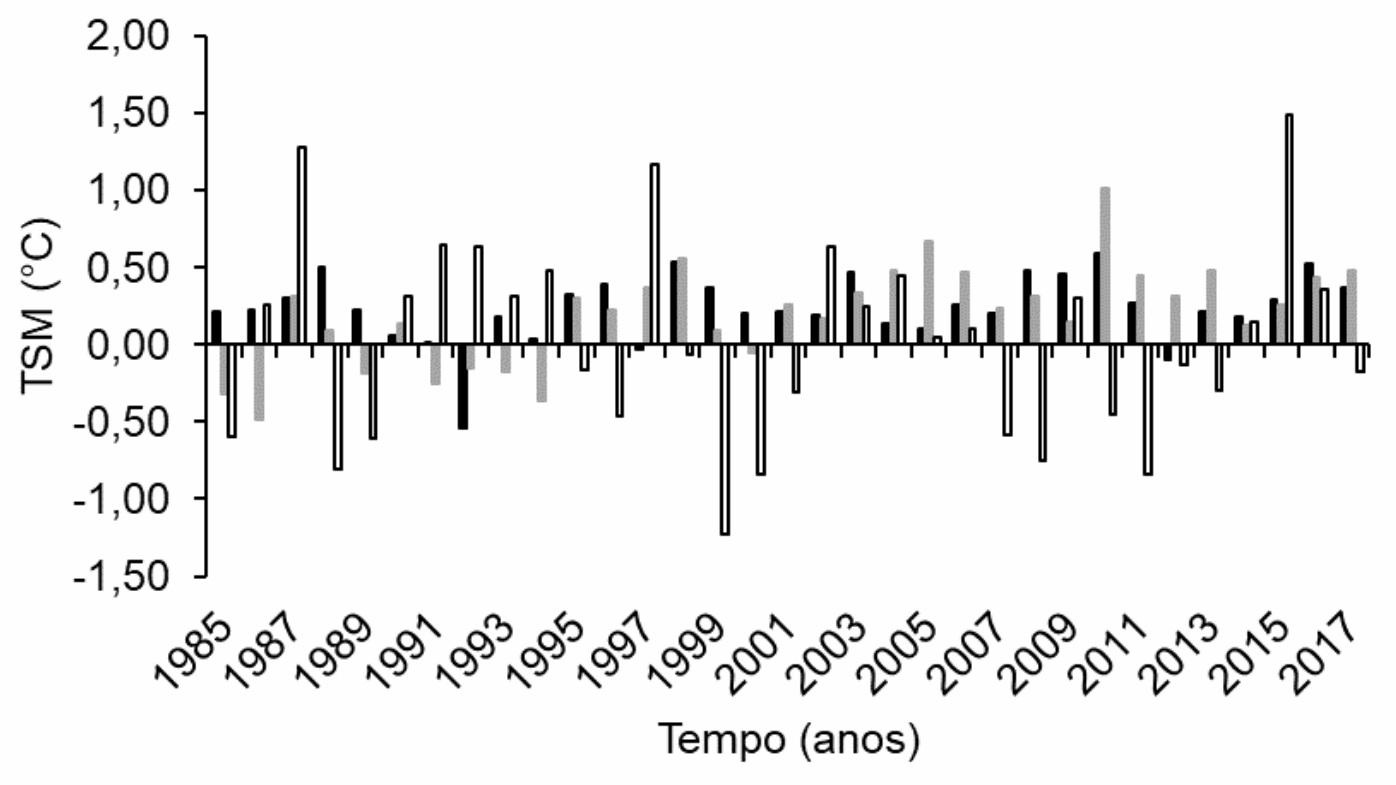

-TSA $=$ TNA IION

FIGURA 2. Anomalia de Temperatura da Superfície do Mar: Temperatura do Atlântico Sul (TSA), Temperatura do Atlântico Norte (TNA) e Índice Oceânico Niño (ION), no período de 1985 a 2017.

Na leitura das anomalias de TSM no Atlântico tropical, pode-se constatar um aquecimento anômalo nos anos de $1986\left(0,22^{\circ} \mathrm{C}\right)$ e $1993\left(0,18^{\circ} \mathrm{C}\right)$, no hemisfério Sul, e resfriamento anormal (mesmo período) de $0,49{ }^{\circ} \mathrm{C}$ e 0,17 , no hemisfério Norte, podendo caracterizar um Dipolo do Atlântico (DA) negativo, proporcionando períodos de estiagem. Na mesma linha de pensamento, observa-se uma situação térmica oposta nas águas oceânicas, apresentando anomalias positivas (Atlântico Norte) nos anos de $1997\left(+0,37^{\circ} \mathrm{C}\right)$ e $2012\left(+0,31^{\circ} \mathrm{C}\right)$ e anomalias negativas (Atlântico Sul) nestes mesmos períodos, $0,03{ }^{\circ} \mathrm{C}$ e $0,09{ }^{\circ} \mathrm{C}$ respectivamente, sugerindo a ocorrência da fase positiva do DA, que favorece a ocorrência de 
precipitação.

O DA é um fenômeno decorrente da interação oceano-atmosfera conhecido como uma mudança anômala da TSM no oceano Atlântico Tropical, desta maneira, quando as águas superficiais deste oceano na porção Norte estão mais aquecidas e as águas do Sul mais resfriadas (DA positivo), há movimentos de subsidência do ar frio e seco dos altos níveis atmosférico inibindo a formação das nuvens e reduzindo a pluviosidade, e, quando as águas superficiais (Atlântico Norte/Sul) estão em situações térmicas opostas, ocorre movimentos de ascendência do ar na região Sul favorecendo a formações de nuvens e aumentando a precipitação (NÓBREGA et al., 2016).

Estudos feitos por Galvíncio et al. (2010) mostram que a variabilidade de precipitação anual é influenciada por osciladores termodinâmicos oceânicos (Pacífico e Atlântico) na região tropical, e Loureiro et al. (2014) argumentam que nos últimos anos muitas cidades no Brasil foram afetadas por tais variações climáticas provocando principalmente estiagens e inundações.

Nóbrega et al. (2014) em suas pesquisas relatam que estudos sobre a variabilidade pluviométrica estão sendo estudas há muito tempo no mundo todo, e ainda ressaltam a importância da compreensão destas oscilações de precipitação, pois quando associadas a anomalias de TSM dos oceanos Atlântico e Pacífico acarretam em sérios impactos econômicos e socioambientais. Santos et al. (2016) reforçam que a bacia hidrográfica amazônica sofre influência significativa de mecanismos oceano-atmosféricos moduladores de precipitação que estão relacionados indiretamente a desastres naturais na Amazônia.

A Figura 3 ilustra a variabilidade pluviométrica na $\mathrm{BH}$ do Araguaia, onde verifica-se que $2015(1.318,4 \mathrm{~mm})$ foi o ano de menor pluviosidade, provavelmente devido ao intenso aquecimento do Pacífico com El Niño forte mesmo observando águas anômalas quentes do Atlântico Sul atuando na região. Enquanto que, 1985 (2095,3 mm) foi o ano de maior precipitação, possivelmente deve estar relacionado a La Niña oriunda do resfriamento anômalo do Pacífico associado ao Dipolo ocorrido no Atlântico e reflexos das águas resfriadas do ano anterior.

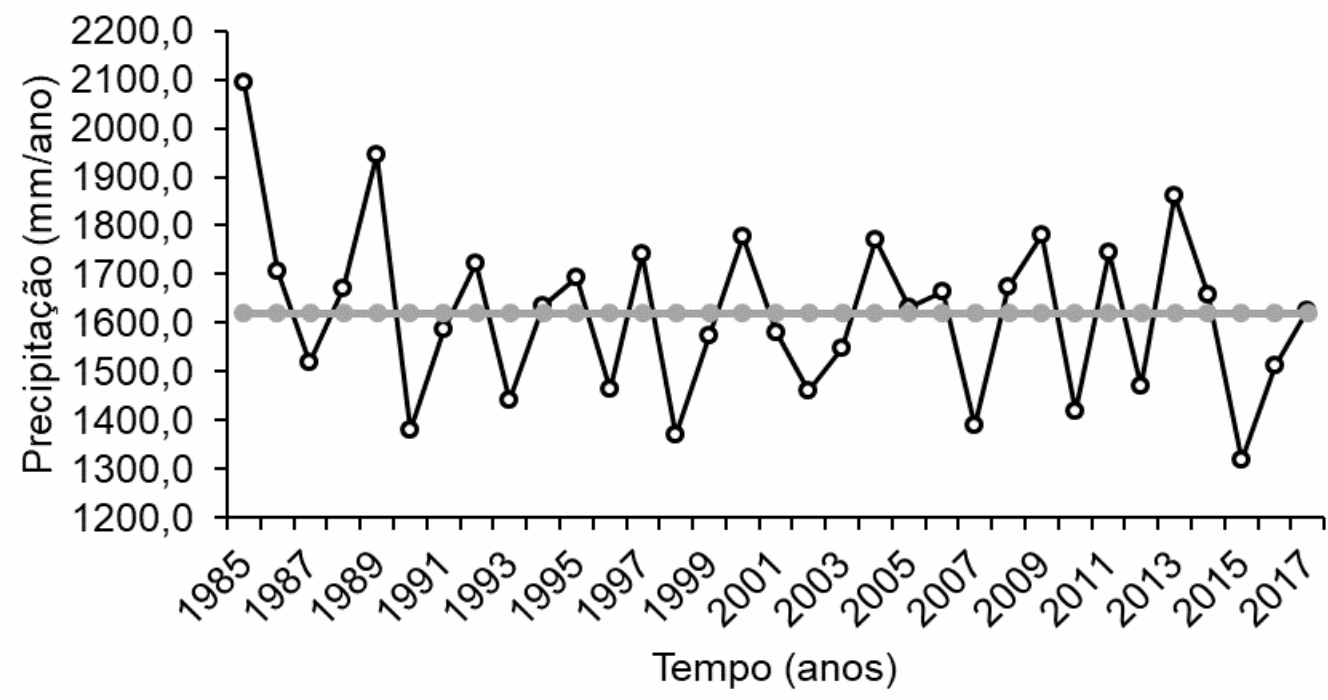

$\multimap-$ Variabilidade Pluviométrica Normal Climatológica

FIGURA 3. Variabilidade Pluviométrica anual: Bacia Hidrográfica do rio Araguaia (1985 - 2017). 
A variabilidade pluviométrica da média mensal na $\mathrm{BH}$ do Araguaia é apresentada na Figura 04. O trimestre mais chuvoso é Dezembro $(263,7 \mathrm{~mm})$, Janeiro $(276,4 \mathrm{~mm})$ e Fevereiro $(243,8 \mathrm{~mm})$, e de acordo com Lopes (2016) neste período há uma forte atuação de um sistema precipitante, a Zona de Convergência do Atlântico Sul (ZCAS), que aumenta consideravelmente a precipitação nessa época. $\mathrm{E}$ o trimestre menos chuvoso corresponde a Junho $(10,9 \mathrm{~mm})$, Julho $(5,2$ $\mathrm{mm}$ ) e Agosto (9,6 mm), onde este clima seco é constatado por Setti (2005).

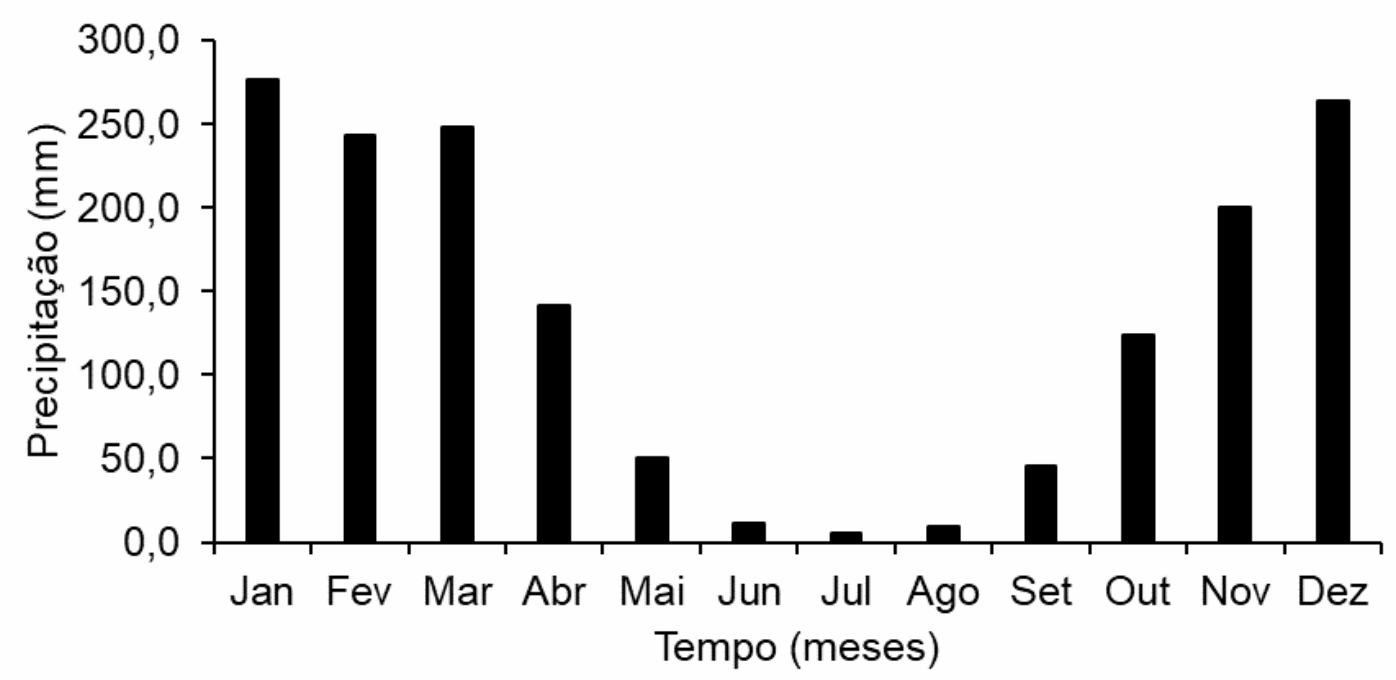

FIGURA 4. Variabilidade Pluviométrica da média mensal: Bacia Hidrográfica do rio Araguaia (1985 - 2017).

A atuação de sistemas sinóticos sobre a região hidrográfica pode ser avaliada ao longo do tempo na Figura 05. Na época das cheias (Nov-Abr) a pluviosidade varia de $59,2 \mathrm{~mm}$ e atinge até $304,8 \mathrm{~mm}$, contribuindo para a recarga hídrica no alto e médio curso do Araguaia (Nov-Dez-Jan), e, concentrando-se no baixo curso do rio no trimestre subsequente, podendo acarretar em eventos de inundações e escorregamento de terra (NASCIMENTO, 2012). Na estação de estiagem (Mai-Out) é evidenciado oscilações mínimas de 0,22 mm e máxima de $97,6 \mathrm{~mm}$, esta escassez hídrica pode ocasionar secas severas, em que este período de baixo volume pluviométrico pode estar associado atuação de centros de alta pressão como a ASSAS que inibe a formação de nuvens, evidenciando a diminuição das chuvas na região. 


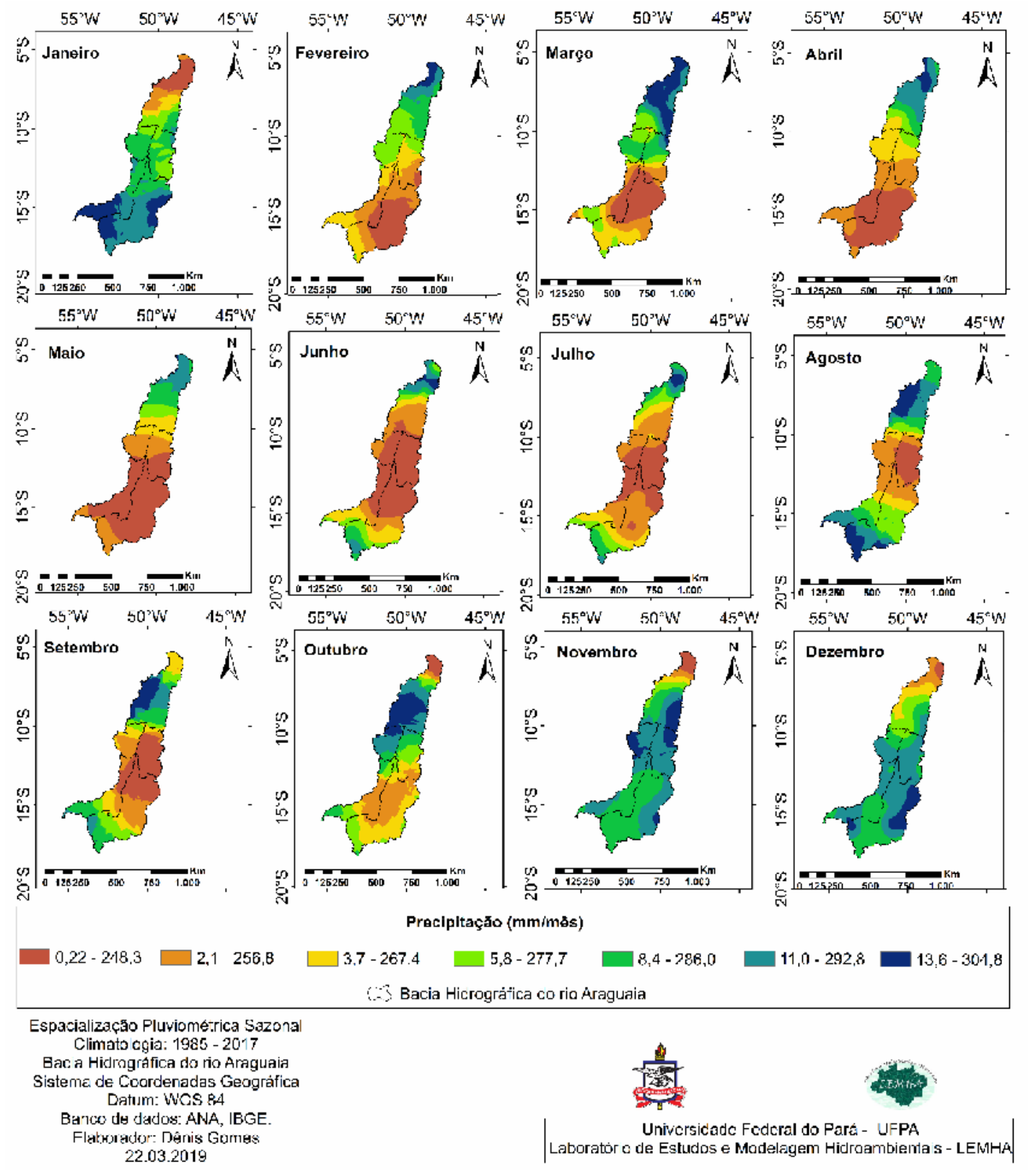

FIGURA 5. Espacialização pluviométrica do acumulado mensal: Bacia Hidrográfica do rio Araguaia (1985 - 2017).

No relativo a recarga da bacia hidrográfica destaca-se a inversão de participação da chuva no alto curso e próximo a foz. A maior frequência de Fevereiro a Agosto encontra-se no Baixo Araguaia (onde há a confluência com o rio Tocantins); e de Novembro a Janeiro no Alto Araguaia e Rio das Mortes. A maior variabilidade de comportamento no ano é verificada no Médio Araguaia e na região do Cantão do Araguaia. Tal observação, ressalta a importância da avaliação entre o tempo do pico da chuva e de recarga nas sub-bacias componentes. Defasagens longas podem ocasionar respostas a variabilidade registrada na Figura 3, tornando mais severos os efeitos das cheias e estiagens.

A Figura 6 ilustra a espacialização pluviométrica da média anual da bacia hidrográfica do rio Araguaia em um período de 33 anos. Os baixos valores 
pluviométricos (1.446,0 mm - 1.610,4 mm) são identificados abrangendo grande parte das sub-bacias do Alto Araguaia (Sul-Sudeste), rio das Mortes (Sudoeste) e Cantão do Araguaia (Centro-Leste). No médio curso do Araguaia a precipitação aumenta (SE - NO) de 1.610,4 mm até $1.741,3 \mathrm{~mm}$, além de observar pluviosidade similar na foz do rio, onde desagua na confluência com o rio Tocantins. A maior frequência pluviométrica $(1741,3 \mathrm{~mm}-1.834,2 \mathrm{~mm})$ concentra-se no Baixo Araguaia, porém antes de sua foz, aumentando o abastecimento hídrico na região.

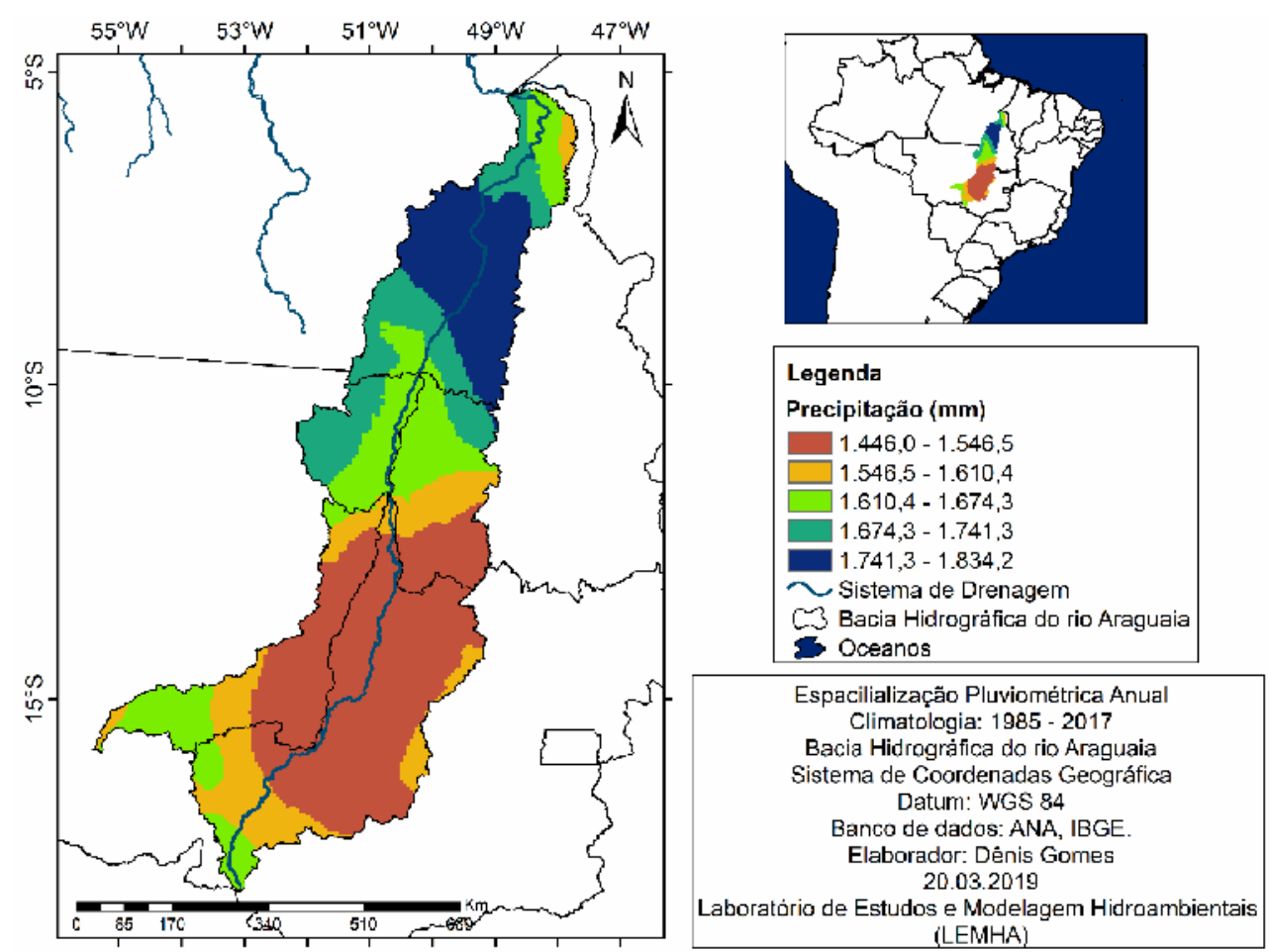

FIGURA 6. Espacialização pluviométrica da média anual: Bacia Hidrográfica do rio Araguaia (1985 - 2017).

Este contexto traz para a bacia do rio Araguaia um diferencial de comportamento em vários aspectos, notadamente no reflexo sobre o aproveitamento das formas de uso da terra na região, principalmente agricultura e pecuária, e no aproveitamento hídrico, que tem na irrigação uma forte demanda (BRASIL, 2006). Referente a relação chuva $x$ vazão Acosta (2007) descreve a maior frequência de vazões de Fevereiro a Abril, desde o Alto Araguaia, abrangendo Janeiro até antes da confluência com o rio das Morte. Este padrão indica que as chuvas de Novembro a Janeiro no Alto Araguaia tem reflexos de descarga até Abril, enquanto que o efeito das chuvas no Baixo Araguaia contribui para a manutenção das cheias de Fevereiro a Abril (Figura 7).

Alencar et al. (2006) afirmam que nesta região central do Brasil a escassez e uso inadequado da água é uma problemática, e reforça apontando impactos antrópicos como crescimento desordenado da população (aumentando o consumo da água e esgoto não tratado), expansão de atividade agrícolas sem supervisão adequada, erosões e assoreamentos dos rios alterando a descarga hídrica padrão, entre outros. 


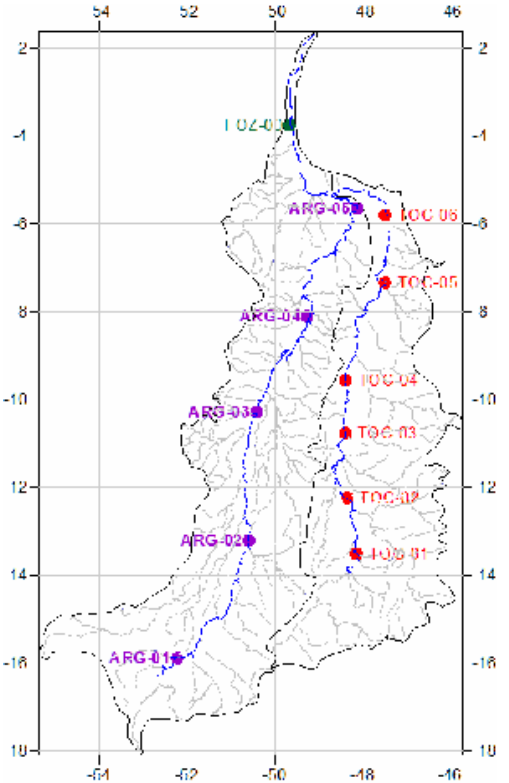

(a)

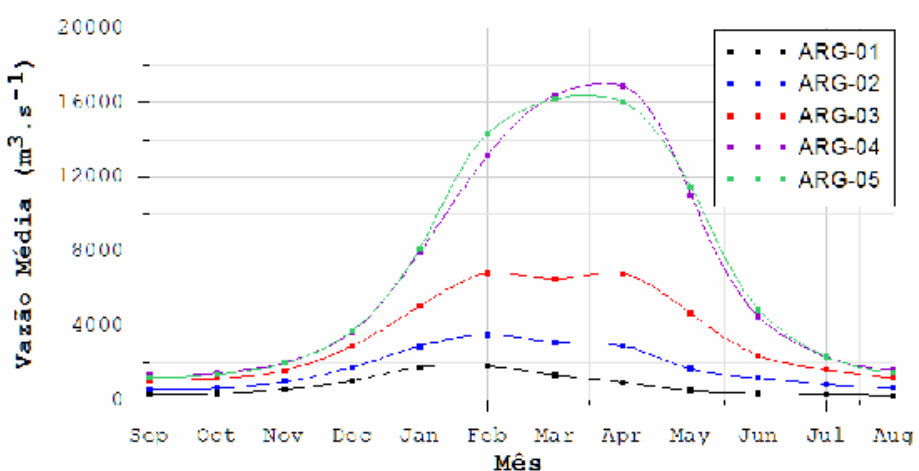

(b)

FIGURA 7. Vazão média mensal observada (m³/s), no período de 1977 a 1985, nas estações ARG-01 a ARG-05 do rio Araguaia: (a) localização das estações na Bacia do Tocantins-Araguaia e (b) distribuição das vazões. Fonte: Acosta (2007).

\section{CONCLUSÃO}

O monitoramento da variabilidade de precipitação a bacia hidrográfica do Araguaia é de suma importância, pois além de se discutir seu impacto na sociedade e apontar as áreas suscetíveis ao clima extremo, pode-se verificar a oscilação da TSM de ambos oceanos que circundam o continente americano e a frequência dos fenômenos reguladores climáticos, que dependendo de sua intensidade podem atuar na região hidrográfica associados com sistemas precipitantes. A distribuição mensal do regime de chuvas reflete no comportamento das vazões, indicando que a bacia apresenta correlação entre os máximos de chuva e de vazão, com uma leve defasagem de 1 mês, mais observada na foz, pois no Alto Araguaia a correspondência é direta. Tais estudos, podem subsidiar modelos hidrológicos, pesquisas sobre a variabilidade do regime e contribuições para a climatologia regional na prevenção dos vários desastres naturais que ocorrem devido a precipitação intensas como produtos de alerta de inundações, enchentes, carreamento de terra, etc.

\section{REFERÊNCIAS}

BRASIL. ANA - Agencia Nacional das Águas. Sistema Nacional de Informação de Recursos Hídricos - SNIRH. Disponível em: < http://www.snirh.gov.br/hidroweb/publico/apresentacao.jsf>. Acessado: 10 de Março de 2019.

ACOSTA, R. Um modelo biosfera-hidrosfera para a bacia do TocantinsAraguaia. 2007, 79 f. Dissertação (Mestrado em Ciências), Instituto de Astronomia, Geofísica e Ciências Atmosféricas, Universidade de São Paulo, São Paulo.

ALENCAR, D. B. S.; SILVA, C. L.; OLIVEIRA, C. A. S. Influência da precipitação no escoamento superficial em uma microbacia hidrográfica do Distrito Federal. Revista 
Agrícola. v. 26, n. 01, p. $103-112,2006$.

ARAÚJO, R. G.; ANDREOLI, R. V.; CANDIDO, L. A. KAYANO, M. T.; SOUZA, R. A. F. A influência do evento El Niño - Oscilação Sul e Atlântico Equatorial na Precipitação sobre as regiões Norte e Nordeste da América do Sul. Revista Acta Amazônica, v. 43, n. 4, p. 469 - 480, 2013.

BARROS, J. R.; BALEIRO, J. C. S. A influência do clima e do tempo do CentroOeste do Brasil nas condições de voo na região. Revista de Geografia da UEG. v. 01, n. 02, p. 25 - 49, 2012.

BERTONNI, J. C.; TUCCI, C. E. M. Precipitação in: TUCCI, C. E. M.; SILVEIRA, A. L. L. (EDS). Hidrologia: Ciência e Aplicação. Porto Alegre: ABRH, 2009.

BORSATO, V. A.; HIERA, M. D.; MARCON, L. S. A Zona de Convergência do Atlântico Sul e a dinâmica atmosférica para o noroeste do Paraná. Revista Brasileira de Climatologia. v. 11, p. $104-118,2012$.

CASTRO, S. S. Erosão hídrica na alta bacia do rio Araguaia: Distribuição, condicionantes, origens e dinâmica atual. Revista do Departamento de Geografia, v. 17, p. $38-60,2005$.

CAZULA, L. P.; MIRANDOLA, P. H. Bacia Hidrográfica - conceitos e importância como unidade de planejamento: um exemplo aplicado na bacia do Ribeirão Lajeado/SP - Brasil. Revista Eletrônica da Associação dos Geógrafos Brasileiros, n. 12, p. $101-124,2010$.

CORRÊA, T. P.; DOHLER, R. E.; DAMBROZ, C. S.; BINOTI, H. B. Aplicação de redes neurais artificiais no preenchimento de falhas de precipitação mensal na região serrana do Espírito Santo. Revista Geociências, v. 35, n. 04, p. 560 - 567, 2016.

CHOUERI, R. B. Biodiversidade e impacto de grandes empreendimentos hidrelétricos na bacia Tocantins-Araguaia: uma análise sistêmica. 2013. 62 f. Dissertação (Mestrado), Universidade de Brasília, Brasília.

DE SOUZA, A. M. L.; ROCHA, E. J. P.; VITORINO, M. I.; SOUZA, P. J. O. P.; BOTELHO, M. N. Variabilidade Espaço-Temporal da Precipitação na Amazônia Durante Eventos ENOS. Revista Brasileira de Geografia Física, v. 08, n. 01, p. 13 $-24,2015$.

BRASIL. EMBRAPA - Empresa Brasileira de Pesquisas Agropecuárias. Sistema Brasileiro de Classificação de solos (SiBCS). Brasília - DF: EMBRAPA, 2018, 75 p.

FÉLIX, V. S. Análise de 40 anos de precipitação pluviométrica da bacia hidrográfica do rio Espinharas - PB. Revista Brasileira de Geografia Física. v. 08, n. 05, p. 1347-1358, 2015.

FERREIRA, A. G.; MELLO, N. G. S. Principais sistemas atmosféricos atuantes sobre a região nordeste do Brasil e a influência dos oceanos Pacífico e Atlântico no clima da região. Revista Brasileira de Climatologia, v. 01, n. 01, p. 15 - 28, 2005.

GALVÍNCIO, J. D.; DANTAS, L. G.; FERNANDES, J. G. Sistemas que favorecem ocorrência de chuva em região semiárida do Nordeste do Brasil: Estudo de caso em São José do Sabugí. Revista de Geografia, v. 27, n. 01, p. 202 - 217, 2010. 
GRIMM, A. M. The El Niño impact on the summer monsson in Brazil: regional processes versus remote influences. Journal Climate, v. 16, p. $263-280,2003$.

BRASIL. INMET - Instituto Nacional de Meteorologia. Normais Climatológicas. Disponível em http://www.inmet.gov.br/portal/.../normaisClimatologicas. Acessado: 24 de Março de 2018.

LOPES, A. F. M. Avaliação da chuva em episódios de ZCAS na região Sudeste do Brasil - Estudo de caso: Bacia do rio Grande. 2016. 130 f. Dissertação (Mestrado), Universidade Federal do Rio de Janeiro, Rio de Janeiro.

LOUREIRO, R. S.; SARAIVA, J. M.; SARAIVA, I.; SENNA, R. C.; FREDÓ, A. S. Estudos dos eventos extremos de precipitação ocorridos em 2009 no estado do Pará. Revista Brasileira de Meteorologia, v. 29, n. especial, p. 83 - 94, 2014.

MELLO, Y. R.; KOHLS, W.; OLIVEIRA, T. M. N. Uso de diferentes métodos para o preenchimento de falhas em estações pluviométricas. Revista Boletim Goiano de Geografia, v. 35, n. 01, p. 112-121, 2017.

BRASIL. MMA - Ministério do Meio Ambiente. Caderno da Região Hidrográfica do Tocantins - Araguaia. Brasília: MMA, 2006.

MOURA, M. N.; VITORINO, M. I.; ADAMI, M. Análise de componentes principais da precipitação pluvial associada a produtividade de soja na Amazônia legal. Revista Brasileira de Meteorologia, v. 22, p. $574-588,2018$.

NASCIMENTO, T. S.; SARAIVA, J. M.; SENNA, R.; AGUIAR, F. E. Preenchimento de falhas em banco de dados pluviométricos com base em dados do CPC (Climate Prediction Center): Estudo de caso do rio Solimões - Amazonas. Revista Brasileira de Climatologia, v. 07, n. 06, p. 143 - 158, 2010.

NASCIMENTO, R. A. A Zona de Convergência do Atlântico Sul - ZCAS e os eventos pluviais intensos no município de Piranga - MG. Revista ACTA Geográfica, Ed. Epec. Climatologia Geográfica, p. 101 - 113, 2012.

NOAA. National Oceanic Administration Agency. Índices Climáticos. Disponível em https://www.esrl.noaa.gov/psd/data/. Acessado: 26 de Fev/ 2019.

NÓBREGA, R. S.; SANTIAGO, G. A. C. F.; SOARES, D. B. Tendências do controle climático oceânico sob a variabilidade temporal da precipitação no nordeste do Brasil. Revista Brasileira de Climatologia, v. 18, n. 12, p. $276-292,2016$.

NÓBREGA, J. N.; SANTOS, C. A. C.; GOMES, O. M.; BEZERRA, B. G.; BRITO, J. I. B. Eventos extremos de precipitação nas mesorregiões da Paraíba e suas relações com a TSM dos oceanos tropicais. Revista Brasileira de Meteorologia, v. 29, n. 02, p. $197-208,2014$.

OliVEIRA, L. F. C.; FIOREZE, A. P.; MEDEIROS, A. M. M.; SILVA, M. A. S. Comparação de metodologias de preenchimento de falhas de séries históricas de precipitação pluvial anual. Revista Brasileira de Engenharia Agrícola e Ambiental, v. 14, n. 11, p. 1186 - 1192, 2010.

ROCHA, T.; MARIANO, Z. F.; BATISTA, D. F.; CABRAL, J. B. P. Variabilidade da temperatura do ar sob os principais sistemas atmosféricos atuantes no estado de Goiás e sua influência nas bacias hidrográficas do Ribeirão Santo Antônio e José Manuel. Revista Geoambiente, n. 30, p. 166 - 180, 2018. 
RODRIGUES, S. A.; BATISTELA, G. C. Uma revisão sobre a disponibilidade hídrica brasileira para geração de energia elétrica. Revista Geoambiente, n. 21, p. 48 - 67, 2013.

SANTOS, C. A.; LIMA, A. M. M.; FRANCO, V. S.; ARAUJO, I. B.; MENEZES, J. F. G.; GOMES, N. M. O. Distribuição espacial da precipitação na bacia hidrográfica do rio Xingu. Revista Nucleus, v. 13, n. 02, p. 223 - 230, 2016.

SANTOS, C. A. C.; MELO, M. M. M. S.; BRITO, M. J. I. B. Tendências de índices de extremo climáticos para o estado do Amazonas e suas relações com a TSM dos oceanos tropicais. Revista Brasileira de Meteorologia. v. 31, n. 01, p. $01-10$, 2016.

SANTOS, C. A.; SERRÃO, E. A. O.; GONÇALVES, L. J. M.; WANZELER, R. T. S.; LIMA, A. M. M. Zoneamento da distribuição da precipitação pluviométrica na bacia hidrográfica do rio Tapajós. Revista Enciclopédia Biosfera, v. 10, n. 18, p. 3092 3106, 2014.

SETTI, D. M. Os climas do cerrado do Centro-Oeste. Revista Brasileira de Climatologia, v. 01, n. 01, p. 29 - 42, 2005.

SOUSA, R. R.; TOLETO, L. G.; TOPANOTTI, D. Q. Oscilação das chuvas na porção centro-oeste do estado do Mato Grosso, entre os anos de 1996 e 2001. Revista Boletim Goiano de Geografia, v. 27, n. 03, p 71 - 89, 2007.

SOUZA, R. O. R. M.; SCARAMUSSA, P. H. M.; AMARAL, M. A. C. M.; NETO, J. A. P.; PANTOJA, A. V.; SADECK, L. W. R. Equações de chuvas intensas para o estado do Pará. Revista Brasileiro de Engenheiro Agrícola e Ambiental, v. 16, n. 09, p. 999 - 1005, 2012.

TEODORO, V. L. I.; TEIXEIRA, D.; COSTA, D. J. L.; FULLER, B. B. O conceito de bacia hidrográfica e a importância da caracterização morfométrica para 0 entendimento da dinâmica ambiental local. Revista UNIARA, n. 20, p. 136 - 157, 2007.

WANDERLEY, H. S.; AMORIM, R. F. C.; CARVALHO, F. O. Variabilidade espacial e preenchimento de falha de dados pluviométricos para o estado de Alagoas. Revista Brasileira de Meteorologia. v. 27, n. 03, 347-354, 2012. 